\title{
ALTERAÇÕES LIGNO-ANATÔMICAS EM Solanum gilo Raddi POR APLICAÇÃO DE CÁLCIO E BORO COMO ESTRATÉGIA DE DEFESA
}

\author{
Ligno-anatomical alteration in Solanum gilo Raddi for the calcium and \\ boron application as defense strategy
}

\author{
Adriana Firmino ${ }^{1}$, Heber dos Santos Abreu ${ }^{2}$, Ana Cristina P. Portugal ${ }^{3}$, \\ Alexandre Miguel do Nascimento ${ }^{4}$, Evandro Lima de Souza ${ }^{5}$, Regina Paula Willemen Pereira, \\ Maria Beatriz de Oliveira Monteiro ${ }^{7}$, Jorge Mitiyo Maêda ${ }^{8}$
}

\begin{abstract}
RESUMO
As plantas lenhosas, de maneira geral, possuem alto teor de lignina, podendo alcançar valores entre 25 a $35 \%$ em relação a massa seca. Valores normalmente encontrados nas plantas arbóreas. Algumas plantas jovens ou de hábitos de crescimentos inferiores aos arbustivos possuem baixo teor de lignina, neste sentido, buscando superar os atuais níveis de lignificação, foram testados em plantas fatores exógenos de estimulação. Um sistema enzimático complexo é responsável pela formação biossintética dos precursores intermediários da lignina, entretanto as peroxidases são responsáveis pela fase determinante da polimerização na parede celular, cuja atividade foi pressupostamente modificada através da aplicação de cálcio e boro, visando aumentar a resistência da planta aos fatores bióticos e abióticos, entre outros. Para tal, utilizou-se a espécie Solanum gilo (família Solanaceae) cultivar Português como planta experimental sob vários tratamentos, monitorando as aplicações quinzenal e semanalmente, nas formas simples e múltiplas de aplicação de $\mathrm{CaSO}_{4}$, $\mathrm{H}_{3} \mathrm{BO}_{3}, \mathrm{CaCl}_{2}$ e $\mathrm{H}_{3} \mathrm{BO}_{3} / \mathrm{CaSO}_{4}, \mathrm{CaSO}_{4} / \mathrm{CaCl}_{2}, \mathrm{CaCl}_{2} / \mathrm{H}_{3} \mathrm{BO}_{3}$ e $\mathrm{CaSO}_{4} / \mathrm{H}_{3} \mathrm{BO}_{3} / \mathrm{CaCl}_{2}$. O tratamento $\mathrm{CaSO}_{4} / \mathrm{CaCl}_{2}$, estatisticamente avaliado, induziu às plantas a uma taxa de lignificação equivalente ao teor de lignina de $19 \%$, superando a testemunha que apresentou $14 \%$. Modificações anatômicas foram também observadas nos elementos de vaso e fibras no que tange ao comprimento, diâmetro e espessura da parede celular. A quantificação da lignina foi realizada segundo o método de Klason. A espectroscopia no infravermelho foi utilizada para análise composicional, revelando a existência de modificação da composição de lignina guaiacílica da planta testemunha (G:S), 1,2:1 para lignina siringílica $(\mathrm{G}: \mathrm{S}), 0,8: 1$ nas plantas que receberam o tratamento $\left(\mathrm{CaSO} 4 / \mathrm{CaCl}_{2}\right)$ quinzenal e semanalmente, respectivamente.
\end{abstract}

Termos para indexação: Lignina, Solanum gilo, peroxidase.

\begin{abstract}
Normally woody plants present high lignin content, even overcoming $35 \%$ from dry weight. Such values are almost found in arboreal plants. However, young plants or plants with lower growth form than tree show low lignin content. In this term, current levels of lignification could be increased by exogenous factor of stimulation. There are complex enzymatic systems responsible for the lignin intermediary precursors formation, however, the peroxidases enzymes have been pointed out as responsible for the lignin polymerization in the cellular wall, whose activity was modified supposedly by calcium and boron application, seeking to increase the plant resistance to the biotic and non biotic factors. The Solanum gilo (Solanaceae family), (Portuguese cultivars) was used as experimental plant according to the several treatments, installed twice (15 days) and once ( 7 days) for month, in the simple and multiple form to CaSO $4, \mathrm{H}_{3} \mathrm{BO}_{3}, \mathrm{CaCl}_{2}$ and $\mathrm{H}_{3} \mathrm{BO}_{3} / \mathrm{CaSO}_{4}, \mathrm{CaSO}_{4} / \mathrm{CaCl}_{2}, \mathrm{CaCl}_{2} / \mathrm{H}_{3} \mathrm{BO}_{3}$ and $\mathrm{CaSO}_{4} / \mathrm{H}_{3} \mathrm{BO}_{3} / \mathrm{CaCl}_{2}$ treatments, respectively. The treatment ( $\left.\mathrm{CaSO}_{4} / \mathrm{CaCl}_{2}\right)$ appraised statistically showed plants with $19 \%$ of lignin, overcoming the standard plants that presented $14 \%$. Anatomical modifications were also observed in the vessels and fibers according to the length, diameter and thickness of the cellular wall. The lignin was quantified by Klason method and the compositional analysis was carried out by infrared spectroscopy, (free extractives samples), revealing the existence of compositional modification from guaiacyl lignin in the standard plants $(\mathrm{G}: \mathrm{S})$ 1.2:1 to syringyl lignin $(\mathrm{G}: \mathrm{S})$ 0.8:1 in the plants that received $\left(\mathrm{CaSO}_{4} / \mathrm{CaCl}_{2}\right)$ twice for month and weekly, respectively.
\end{abstract}

Index terms: Lignin, Solanum gilo, peroxidase.

\section{(Recebido para publicação em 22 de setembro de 2004 e aprovado em 27 de março de 2006)}

\section{INTRODUÇÃO}

A lignina além das funções inerentes a fisiologia das plantas, apresenta-se como uma barreira de defesa física e química, dificultando a penetração de fungos, bactérias, consumo por insetos, em fim protegendo as plantas contra os fatores bióticos e abióticos, advindo do

${ }^{1}$ Mestre em Ciências Ambientais e Florestais - Departamento de Produtos Florestais - Universidade Federal Rural do Rio de Janeiro - BR 465 $\mathrm{Km} 7$ - 23.890-000 - Seropédica, RJ.

2Professor Adjunto do Departamento de Produtos Florestais/UFRRJ - BR 465 - Km 7 - 23.890-000 - Seropédica, RJ - abreu@ufrrj.br

${ }^{3}$ Pesquisadora da EMBRAPA-Fortaleza - Rua Dra Sara Mesquita, 2270 - Planalto do Pici - 60.511-110 - Fortaleza, CE.

${ }^{4}$ Professor Adjunto do Departamento de Produtos Florestais/UFRRJ - BR 465 - Km 7 - 23.890-000 - Seropédica, RJ.

${ }^{5}$ Engenheiro Florestal - Departamento de Produtos Florestais - Universidade Federal Rural do Rio de Janeiro - BR 465 - Km 7 - $23.890-000$ Seropédica, RJ.

${ }^{6}$ Mestranda em Ciências Ambientais e Florestais - Departamento de Produtos Florestais - Universidade Federal Rural do Rio de Janeiro - BR 465 $\mathrm{Km} 7$ - 23.890-000 - Seropédica, RJ.

${ }^{7}$ Mestranda em Ciências Ambientais e Florestais - Departamento de Produtos Florestais - Universidade Federal Rural do Rio de Janeiro - BR 465 Km 7 - 23.890-000 - Seropédica, RJ.

${ }^{8}$ Professor Adjunto do Departamento de Silvicultura-Florestais/IF - Universidade Federal Rural do Rio de Janeiro/UFRRJ - BR 465 - Km 7 23.890-000 - Seropédica, RJ. 
ambiente. Tais funções justificam-se por ser encontrada principalmente na parede celular e na lamela média de células xilemáticas e de outras partes de diferentes origens citológicas, tais como: folha, caule, casca e raízes. Formada pela oxidação desidrogenativa, catalisada pela peroxidase (isoenzimas) na presença $\mathrm{H}_{2} \mathrm{O}_{2}$, destaca-se por ser o maior produto de uma via metabólica que garante a manutenção da vida dos vegetais superiores (DAVIN \& LEWIS, 1995). $\mathrm{O}$ acúmulo da lignina, portanto, advém dos mecanismos bioquímicos essenciais para a sobrevivência de um vegetal. As variações quantitativas de lignina nas plantas foram influenciadas por uma série de fatores. $O$ fator edáfico, acompanhado de uma situação extrema de estresse ambiental a milhões de anos atrás, foi responsável pelas mais marcantes modificações fenotípicas observadas em plantas contemporâneas, conforme Bosísio (1996).

Davin \& Lewis (1995) constataram que durante o crescimento e desenvolvimento das plantas vasculares, metabólitos secundários (fenilpropanoídicos) são acumulados nos tecidos e que muitos estariam comprometidos com a estrutura da parede celular, dandolhes resistência a compressão e impermeabilidade, assim como exercendo papel importante no transporte de nutrientes e retenção de fluídos.

A atividade da peroxidase promove o endurecimento e a perda da elasticidade da parede celular (SANCHEZ et al., 1989). A presença de cálcio (nutriente universal) também interfere sobre a lignificação, formando sistema coordenados (peroxidase- $\mathrm{H}_{2} \mathrm{O}_{2}$ ) dentro da parede celular. Por outro lado, as deficiências do cálcio e boro afetam os processos fisiológicos da planta interferindo no transporte de açúcares, na síntese da parede celular, lignificação, no metabolismo de carboidratos, RNA e AIA (ácido indol acético), respiração e integridade da membrana plasmática (CAKMAK \& ROHMHELD, 1997). Neste sentido, o processo de incorporação destes elementos destaca-se como um fator importante para maximizar o processo de lignificação.

A peroxidase possui dois íons de cálcio e catalisa reações oxi-redutivas levando à redução do peróxido de hidrogênio e conseqüentemente à lignificação. A presença de $\mathrm{Ca}^{++}$na cadeia de íons pécticos associada aos dímeros ou oligômeros forma uma estrutura conhecida como "zona de junção", ocorrendo em associação com a peroxidase e pectinas favorecendo a atividade e a estabilidade desta enzima (PENEL et al., 1994).

De forma geral, o cálcio assume papel no sistema regulatório funcional da célula, tanto no citoplasma quanto na parede celular. A busca do conhecimento para aumentar a resistência parte da premissa de que essa resistência pode ser discutida dentro dos parâmetros biossintéticos da lignina.

Objetivou-se com esta pesquisa estudar a influência do cálcio e do boro, no processo de lignificação, assim como, verificar a flexibilidade anatômica do caule do jiloeiro (Solanum gilo Raddi cv. Português), visando a elevação da taxa de lignificação, de maneira a contribuir para o aumento da resistência dessa cultivar às doenças e pragas.

\section{MATERIAL E MÉTODOS}

Este trabalho foi conduzido em casa-de-vegetação experimental da EEI/PESAGRO-RIO e no campus da Universidade Federal Rural do Rio de Janeiro.

As sementes do jiloeiro (Solanum gilo Raddi cv. Português) foram semeadas em vasos plásticos com capacidade para sete litros. Foi realizada análise do solo e logo em seguida, foi acrescido de superfosfato simples com $7 \mathrm{~g}$ por vaso e cloreto de potássio com 1,2 g por vaso. Esses produtos foram misturados com o solo de cada vaso. $\mathrm{O} \mathrm{pH}$ 6,5 do solo foi corrigido com adição de sulfato de cálcio.

Os tratamentos constituíram-se de: Testemunha $\left(\mathrm{H}_{2} \mathrm{O}\right), \mathrm{CaSO}_{4}, \mathrm{H}_{3} \mathrm{BO}_{3}, \mathrm{CaCl}_{2}$ e $\mathrm{H}_{3} \mathrm{BO}_{3} / \mathrm{CaSO}_{4}, \mathrm{CaSO}_{4} / \mathrm{CaCl}_{2}$, $\mathrm{CaCl}_{2} / \mathrm{H}_{3} \mathrm{BO}_{3}$ e $\mathrm{CaSO}_{4} / \mathrm{H}_{3} \mathrm{BO}_{3} / \mathrm{CaCl}_{2}$. Os dados foram analisados estatisticamente utilizando delineamento inteiramente casualizado em arranjo fatorial ( $12 \times 4)$, sendo usado quatro repetições por tratamento, num total de 48 vasos. Os dados foram submetidos à análise de variância, utilizando-se o teste de Tukey, ao nível de 5\% de probabilidade, teste de normalidade em nível de $1 \%$ de probabilidade, e teste de Kolmogorov-Smirnov (CAMPOS, 1983; GOMES, 1985). As aplicações ocorreram em duas formas para cálcio foliar $\left(\mathrm{CaCl}_{2}\right)$, nas concentrações equivalentes a $5 \mathrm{~g} / 1$ e $\mathrm{H}_{3} \mathrm{BO}_{3}(1 \mathrm{~g} / \mathrm{l})$ no interstício de $15 \mathrm{em} 15$ dias (quinzenal) e em 7 em 7 dias (semanal). A aplicação de sulfato de cálcio $\left(\mathrm{CaSO}_{4}\right)$ no solo ocorreu em uma única vez.

As análises anatômicas foram obtidas da porção lenhosa próxima a base dos caules a $5 \mathrm{~cm}$ acima do colo das plantas (três meses de idade). Foram realizados cortes histoquímicos (corte transversal) de $25 \mathrm{~mm}$ de espessura, sendo o material fixado em álcool 70\%, (BURGER \& RICHTER, 1991), e depois parte do material foi macerado, cada amostra foi submersa em água oxigenada e ácido acético, tendo ficado $48 \mathrm{~h}$ na estufa, para que o material dissociasse. Depois de dissociado o material foi lavado com água destilada e corado com safranina alcóolica $1 \%$. O comprimento e espessura da parede do vaso, diâmetro do vaso, espessura da parede celular, diâmetro total e diâmetro do lume da fibra (corte transversal), para 
observação de ocorrência de lignificação, por testes histoquímicos em tecido fresco com floroglucina. A segunda etapa foi feita com o material fixado em álcool $70 \%$ para confecção das lâminas.

A determinação do teor de lignina foi realizada a partir do material vegetal (caule) sem casca e seco em estufa a $65^{\circ} \mathrm{C}$. Uma certa quantidade deste material moído foi homogeneizado a 20-80 mesh de diâmetro, das quais foram extraídas continuamente com éter etílico, acetona, metanol e em seguida com água em um extrator do tipo Soxhlet, durante $60 \mathrm{~h}$ ininterruptas para cada extração. O material livre de extrativos foi previamente seco, até peso constante, em um dessecador sob vácuo, contendo anidrido fosfórico. Em torno de trezentos miligramas de amostra seca livre de extrativos (cinco repetições) foram utilizados para determinação do teor de lignina, segundo o método de Klason (LIN \& DENCE, 1992) modificado por Effland (1977).

A composição da lignina foi estimada empiricamente através dos espectros no infravermelho, de acordo com a relação em porcentagem entre as intensidades dos sinais 1328 e $1268 \mathrm{~cm}^{-1}$. Os espectros no infravermelho foram registrados por um espectrômetro por transformada de Fourier, Perkin-Elmer, utilizando $2 \mathrm{mg}$ de material lignocelulósico livre de extrativos e $200 \mathrm{mg}$ de $\mathrm{KBr}$ anidro. Os sinais em 3500, 3000-2980, 1740, 1690, 1670, 1600, 1500, 1460,1328 e $1268 \mathrm{~cm}^{-1}$ foram também identificados, entretanto, apenas os sinais em 1328 e $1268 \mathrm{~cm}^{-1}$ foram considerados para análise composicional (LIN \& DENCE, 1992).

Os dados foram submetidos à análise de variância, utilizando-se de teste de Tukey, em nível de 5\% de probabilidade, agrupando-se as médias em classes distintas. O teste de normalidade em nível de $1 \%$ de probabilidade e teste de Kolmogorov-Smirnov" foram aplicados (CAMPOS, 1983; GOMES, 1985).

\section{RESULTADOS E DISCUSSÃO}

$\mathrm{O}$ efeito do cloreto de cálcio $\left(\mathrm{CaCl}_{2}\right)$, ácido bórico $\left(\mathrm{H}_{3} \mathrm{BO}_{3}\right)$ e sulfato de cálcio $\left(\mathrm{CaSO}_{4}\right)$ sobre o sistema de lignificação levaram as plantas a apresentarem diferenças significativas, segundo vários parâmetros. No tratamento quinzenal, a lignificação foi mais expressiva, tendo alcançado o valor máximo de $19,50 \%$. O boro nos tratamentos $\left(\mathrm{CaCl}_{2} / \mathrm{H}_{3} \mathrm{BO}_{3}\right)$ e $\left(\mathrm{CaSO}_{4} / \mathrm{H}_{3} \mathrm{BO}_{3} / \mathrm{CaCl}_{2}\right)$ contribuiu para diminuir a eficiência da mobilidade do $\mathrm{Ca}^{++}$, tendo um efeito menor sobre a lignificação (FAWZIA et al., 1994). $\mathrm{O} \mathrm{CaCl}_{2}$ com aplicação semanal ao contrário da aplicação quinzenal teve seu efeito maximizado. A explicação para tal, parte da premissa que a citoxidade do $\mathrm{Ca}^{++},\left(\mathrm{Ca}^{++}\right.$em alta concentração), torna-se tóxico ao citoplasma, afetando o movimento do mesmo do citoplasma para a parede celular. Maclaughlin \& Wimmer (1999), literalmente, mostram que o fator toxidez tem conseqüência sobre a precipitação do fosfato inorgânico prejudicando o metabolismo de fosforilação dentro da célula. A manutenção do $\mathrm{Ca}^{++}$em escala micromolar torna-se necessário à função celular dentro do citoplasma, exigindo energia para o transporte de cálcio ancorado à membrana plasmática, conseqüentemente através dos canais específicos bombeadores que promovem o balanço entre a exportação e o influxo de cálcio. $\mathrm{O} \mathrm{Ca}^{++}$em doses acumulativas não migra totalmente, o que regularmente formaria um sistema de coordenação com peroxidase dentro da parede celular (HUBER, 1981). A regulação entre a acumulação e a exportação de $\mathrm{Ca}^{++}$do citoplasma à parede deve-se ao processo de osmose, que regula a concentração dos íons de $\mathrm{Ca}^{++}$em ambos ambientes da célula. Neste caso, o desequilíbrio gerado pela alta concentração do cálcio desencadeou um processo provável de estresse.

Observou-se também que $\mathrm{CaSO}_{4}$ e $\mathrm{H}_{3} \mathrm{BO}_{3}$ aplicados isoladamente poucos contribuíram para o processo de lignificação. Este resultado permitiu propor que o processo de lignificação sofreu maior influência do tratamento binário e simples, que continha $\mathrm{CaCl}_{2}$, principalmente com aplicação quinzenal. A combinação tripla com a participação do boro na aplicação quinzenal aumentou a lignificação promovendo um acúmulo de $18,54 \%$ de lignina. Neste caso o efeito sobre a lignificação foi também eficiente ficando um pouco abaixo do tratamento $\left(\mathrm{CaSO}_{4} / \mathrm{CaCl}_{2}\right)$, aplicado quinzenalmente. Este efeito pode ser visualizado na Figura 1.

A deficiência de boro deve estar associada ao declínio da atividade da peroxidase, o que por um lado causaria a acumulação de substâncias fenólicas (FAWZIA et al., 1994) acrescidas do aumento da atividade da enzima fenilalaninamônia-liase (PAL) no citoplasma (FAWZIA et al., 1994), enquanto, por outro lado o excesso de Boro não estimula eficientemente o aumento da atividade da peroxidase no caule (PALAVAN-UNSAL et al., 1999). Observou-se que todos os tratamentos que receberam boro, só tiveram efeitos maiores quando associados ao cálcio.

\section{Efeito dos tratamentos sobre o comprimento, espessura da parede e diâmetro de vaso}

No tratamento com $\left(\mathrm{H}_{3} \mathrm{BO}_{3} / \mathrm{CaSO}_{4} / \mathrm{CaCl}_{2}\right)$ quinzenal, o comprimento dos vasos atingiu valor médio de 261,43 mm, enquanto no tratamento com $\mathrm{CaSO}_{4} / \mathrm{CaCl}_{2}$ quinzenal, observou-se um aumento de comprimento entorno de 305,62 mm. A presença do cálcio somada aos demais nutrientes induziu a diminuição do comprimento

Ciênc. agrotec., Lavras, v. 30, n. 3, p. 394-401, maio/jun., 2006 
de vaso, uma resposta esperada, já que o aumento do teor de lignina com aplicação de cálcio (quinzenal) aumenta a rigidez da parede celular impedindo o aumento do volume celular. Como o elemento de vaso naturalmente possui menor conteúdo de lignina do que a fibra por ser um tecido de condução, observou-se que somente no tratamento com interação tripla $\left(\mathrm{H}_{3} \mathrm{BO}_{3} /\right.$ $\left.\mathrm{CaSO}_{4} / \mathrm{CaCl}_{2}\right)$ e dupla $\left(\mathrm{CaSO}_{4} / \mathrm{CaCl}_{2}\right)$, houve aumento da lignificação concomitantemente com a redução do comprimento dos vasos. Verificou-se também variações no diâmetro dos vasos e na espessura da parede (Figuras 2, 3 e 4 ).
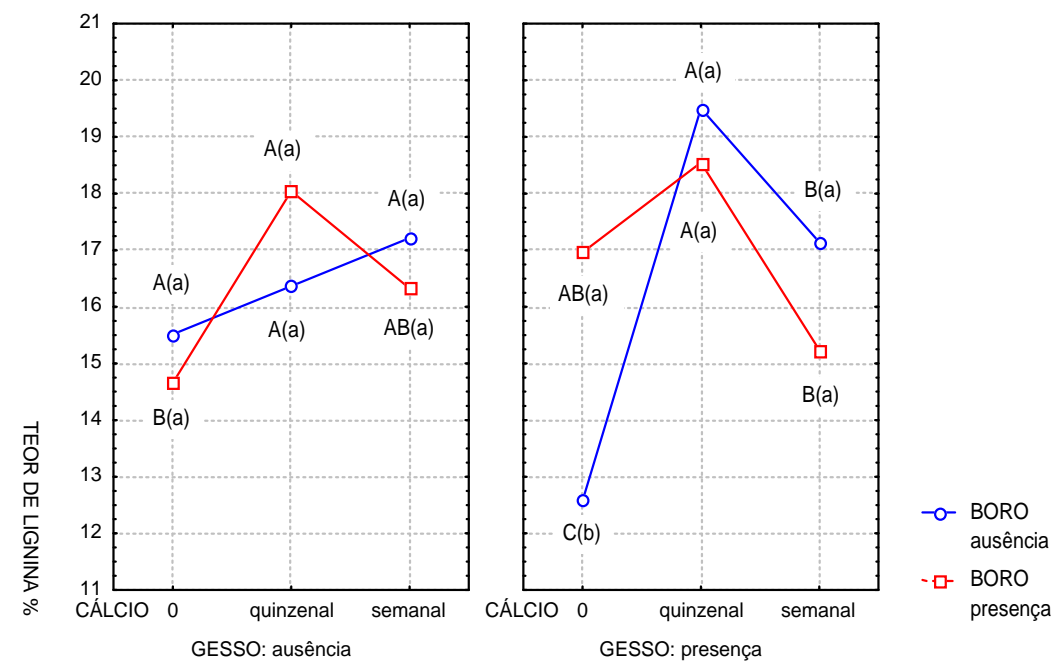

FIGURA 1 - Influência do tratamento triplo $\left(\mathrm{H}_{3} \mathrm{BO}_{3} / \mathrm{CaSO}_{4} / \mathrm{CaCl}_{2}\right)$ sobre o teor de lignina em (\%) do caule de Solanum gilo.

Letra minúscula distinta mostra diferença estatística, em nível de 5\% de significância, entre ausência e presença de boro e letras maiúsculas entre diferentes níveis de cálcio.
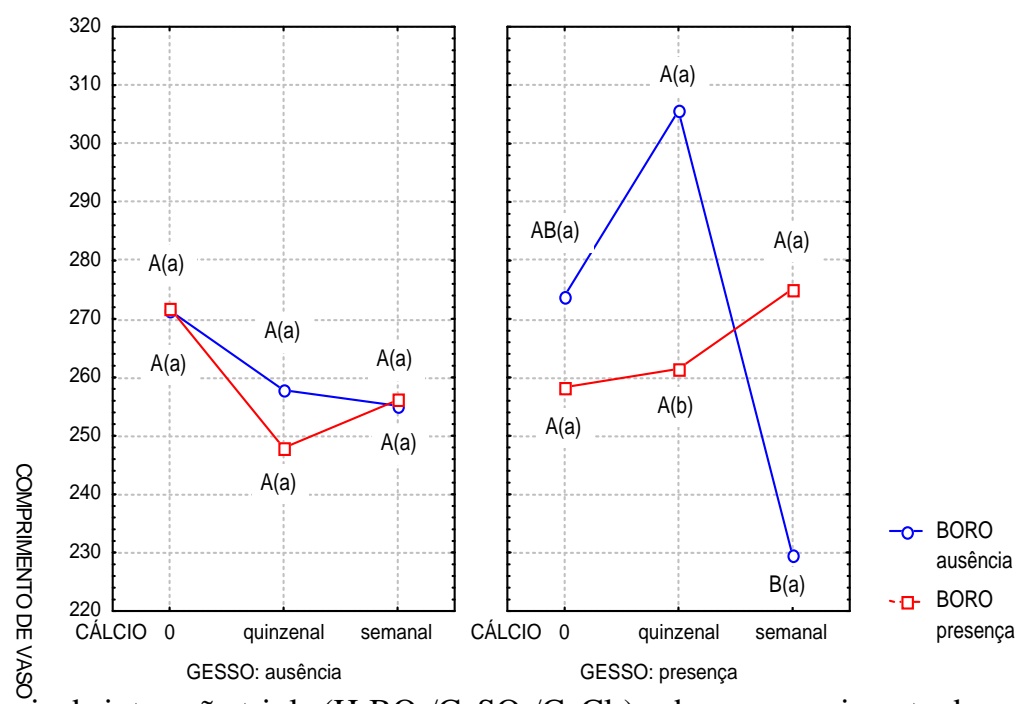

FIGURA 2 - Influência da interação tripla $\left(\mathrm{H}_{3} \mathrm{BO}_{3} / \mathrm{CaSO}_{4} / \mathrm{CaCl}_{2}\right)$ sobre o comprimento de vaso em $(\mu \mathrm{m})$ do caule de Solanum gilo.

Letra minúscula distinta mostra diferença estatística, em nível de 5\% de significância, entre ausência e presença de boro e letras maiúsculas entre diferentes níveis de cálcio.

Ciênc. agrotec., Lavras, v. 30, n. 3, p. 394-401, maio/jun., 2006 

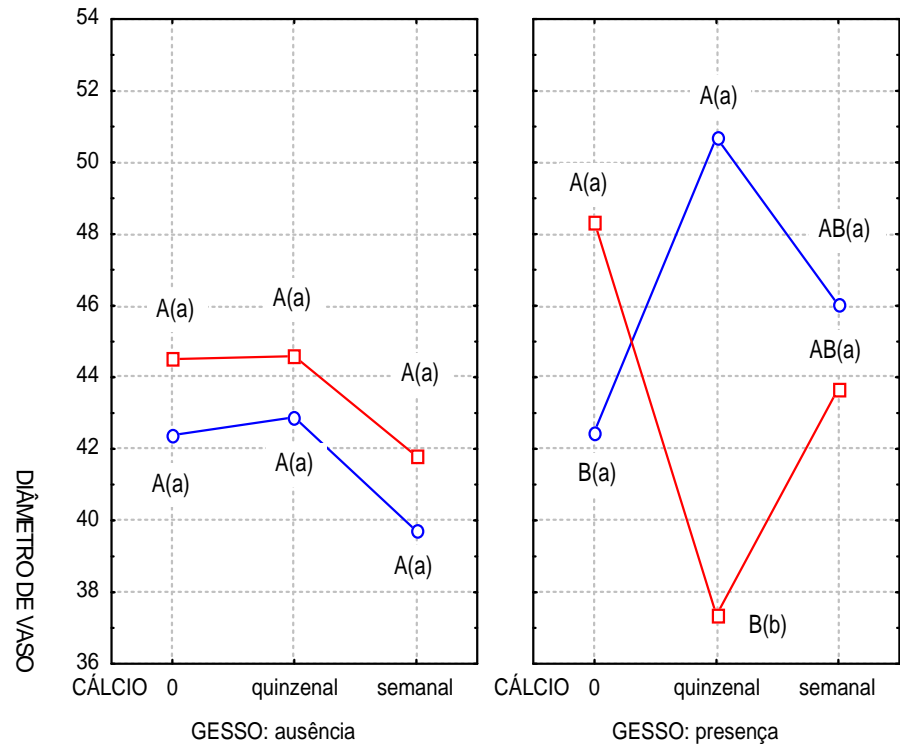
-o- BORO
ausência
- ㅁ BORO
presença

FIGURA 3 - Diâmetro médio de vaso em $(\mu \mathrm{m})$ do caule de Solanum gilo, tratadas com $\left(\mathrm{H}_{3} \mathrm{BO}_{3} / \mathrm{CaSO}_{4}\right)$.

Letra minúscula distinta mostra diferença estatística, em nível de 5\% de significância, entre ausência e presença de boro e letras maiúsculas entre diferentes níveis de cálcio.

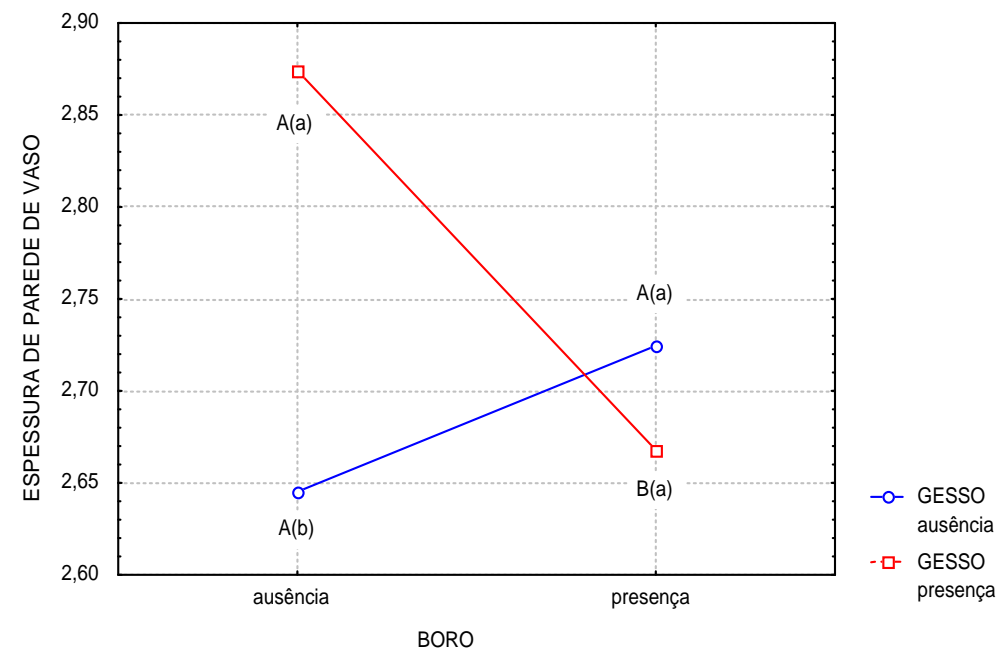

FIGURA 4 - Influência do tratamento $\left(\mathrm{H}_{3} \mathrm{BO}_{3} / \mathrm{CaSO}_{4}\right)$ sobre a espessura da parede de vaso em $(\mu \mathrm{m})$ do caule de Solanum gilo.

Letra minúscula distinta mostra diferença estatística, em nível de 5\% de significância, entre ausência e presença de boro e letras maiúsculas entre diferentes níveis de cálcio.

As médias observadas para os diâmetro e comprimento de vaso apresentaram o mesmo comportamento no tratamento $\left(\mathrm{CaSO}_{4} / \mathrm{CaCl}_{2}\right)$ quinzenal, promovendo o aumento em comprimento. As plantas que foram submetidas ao tratamento $\left(\mathrm{H}_{3} \mathrm{BO}_{3} / \mathrm{CaSO}_{4}\right)$, tiveram o diâmetros dos vasos aumentado para 48,33 mm, entretanto, a aplicação de $\mathrm{CaCl}_{2}$ (quinzenal) diminuiu os diâmetros para $37,35 \mathrm{~mm}$, ao contrário, a aplicação semanal aumentou o diâmetro para 43,68 mm. A espontânea interação do Boro com grupos dióis em posição cis, (ácido bórico e íons

Ciênc. agrotec., Lavras, v. 30, n. 3, p. 394-401, maio/jun., 2006 
boratos) podem reagir e formar complexos com açúcares e fenóis (MATOH \& KOBAYASHI, 1998), promovendo a diminuição da porosidade da parede celular, interferindo na ação cimentadora da lamela média, e na transmissão de sinais entre células através da parede celular. Um outro aspecto foi o aumento do nível de boro absorvido com o aumento o nível de absorção de $\mathrm{Ca}^{++}$. Isto permitiu sugerir que, a presença de Boro contribui para o aumento do diâmetro do vaso. Além disso, a formação de substâncias pécticas (pectatos de cálcio) pode regular a absorção do boro.

\section{Efeito dos tratamentos sobre o diâmetro da fibra}

As análises permitiram verificar que o tratamento com $\mathrm{CaCl}_{2}$-semanal aplicado isoladamente, promoveu uma diminuição do diâmetro de fibra a um valor igual a 20,30 mm, que foi superior ao tratamento quinzenal $(17,40 \mathrm{~mm})$ se comparada a testemunha $(28,07 \mathrm{~mm})$. Na realidade, o íon $\mathrm{Ca}^{++}$ forma ligações cruzadas entre pectatos através de grupos carboxílicos de ácidos urônicos, portanto elevadas doses de $\mathrm{Ca}^{++}$podem inferir baixa afinidade às substâncias pécticas, aumentando e diminuindo as interações entre pectinas/ peroxidase $/ \mathrm{Ca}^{++}$. Isto sugere que a rigidez da parede celular provavelmente aumentou em decorrência do aumento do teor de lignina sob este tratamento (CARPIN et al., 1999).

Com o tratamento com $\mathrm{CaCl}_{2}$ quinzenal e semanal aplicados isoladamente verificou-se uma diminuição do diâmetro de vaso para 17,40 e 20,30 mm, respectivamente apresentando comportamentos ligeiramente opostos. Enquanto nos vasos, não houve expressivo aumento, entretanto, nas fibras a diminuição do diâmetro foi considerada muito expressiva.

$\mathrm{O}$ efeito do tratamento combinando com $\left(\mathrm{H}_{3} \mathrm{BO}_{3} /\right.$ $\left.\mathrm{CaSO}_{4} / \mathrm{CaCl}_{2}\right)$ semanal $(21,61 \mathrm{~mm})$ diferiu da aplicação quinzenal que foi de $18,18 \mathrm{~mm}$. Foi possível verificar que o boro aplicado isoladamente $(20,53 \mathrm{~mm})$ teve o mesmo efeito sobre o diâmetro da fibra que no tratamento com $\mathrm{H}_{3} \mathrm{BO}_{3} /$ $\mathrm{CaSO}_{4} / \mathrm{CaCl}_{2}$ semanal.

\section{Efeito dos tratamentos sobre o comprimento e espessura} da parede da fibra

$\mathrm{O}$ tratamento com $\left(\mathrm{CaSO}_{4} / \mathrm{CaCl}_{2}\right)$ quinzenal, afetou o comprimento da fibra elevando para $534,43 \mathrm{~mm}$, diferindo da aplicação semanal, na qual o comprimento chegou a 444,86 mm, enquanto $\mathrm{CaSO}_{4}$ aplicado isoladamente alterou o comprimento da fibra para $463,90 \mathrm{~mm}$.

Isto coaduna com a hipótese de que o $\mathrm{Ca}^{++}$ depositado nas células promove aumento do comprimento celular e também aumento das atividades enzimáticas.

$\mathrm{O}$ tratamento com $\left(\mathrm{H}_{3} \mathrm{BO}_{3} / \mathrm{CaSO}_{4} / \mathrm{CaCl}_{2}\right)$ quinzenal, também modificou o comprimento da fibra de 436,07 mm, diferindo do tratamento $\left(\mathrm{H}_{3} \mathrm{BO}_{3} / \mathrm{CaSO}_{4}\right)$ que modificou positivamente o comprimento para $502,32 \mathrm{~mm}$, em relação a testemunha. $\mathrm{O}$ mesmo acontecendo com o tratamento com $\left(\mathrm{H}_{3} \mathrm{BO}_{3} / \mathrm{CaSO}_{4} / \mathrm{CaCl}_{2}\right)$ semanal, em que verificou-se o valor de 502,04 mm (Figura 6).

$\mathrm{O}$ tratamento com $\left(\mathrm{H}_{3} \mathrm{BO}_{3} / \mathrm{CaSO}_{4}\right)$ aumentou a espessura da parede da fibra para $4,15 \mathrm{~mm}$, enquanto os tratamentos com $\left(\mathrm{H}_{3} \mathrm{BO}_{3} / \mathrm{CaSO}_{4} / \mathrm{CaCl}_{2}\right)$ quinzenal e semanal, diminuíram o diâmetro para $3,09 \mathrm{~mm}$ e $3,16 \mathrm{~mm}$, respectivamente (Figura 7)
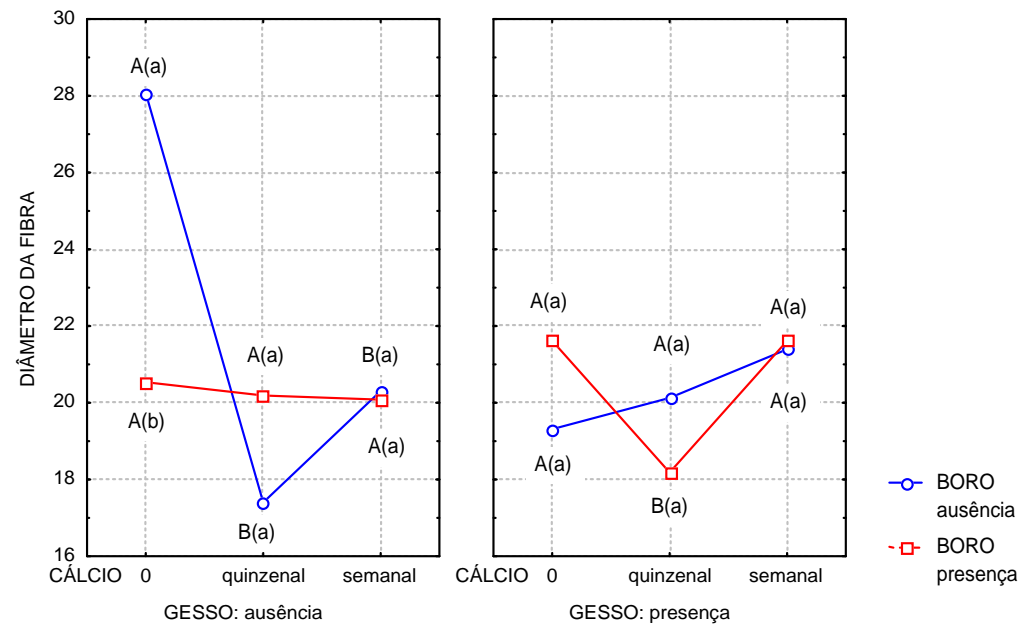

FIGURA 5 - Influência da interação tripla $\left(\mathrm{H}_{3} \mathrm{BO}_{3} / \mathrm{CaSO}_{4} / \mathrm{CaCl}_{2}\right)$ sobre diâmetro da fibra em ( $\mu$ m) do caule de Solanum gilo.

Letra minúscula distinta mostra diferença estatística, em nível de 5\% de significância, entre ausência e presença de boro e letras maiúsculas entre diferentes níveis de cálcio. 

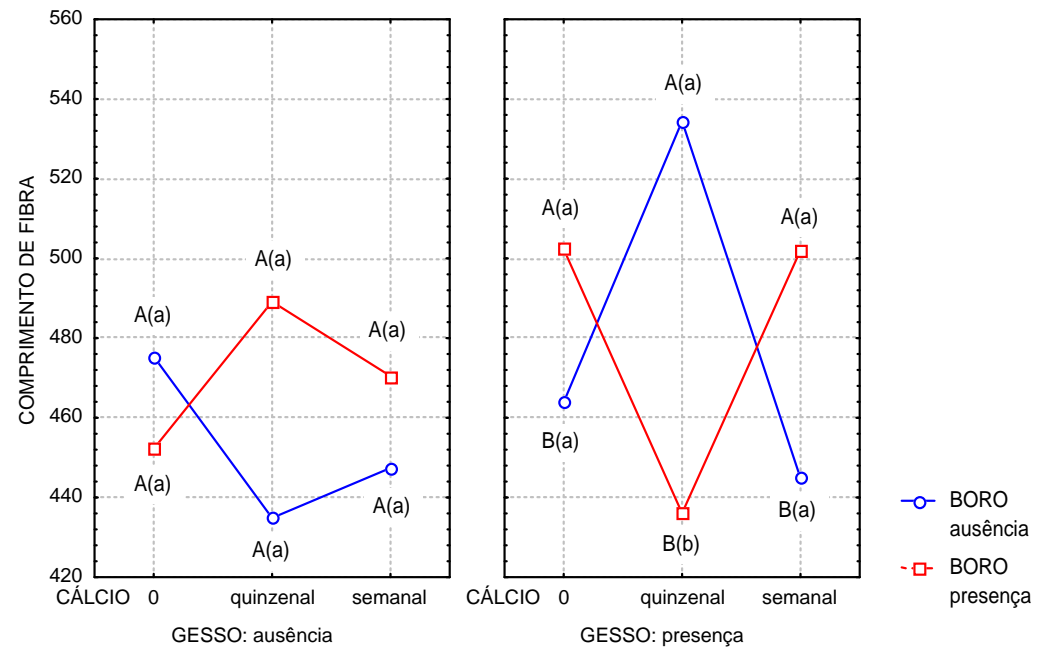

FIGURA 6 - Influência da interação tripla dos nutrientes sobre o comprimento de fibra em ( $\mu \mathrm{m})$ do caule de Solanum gilo.

Letra minúscula distinta mostra diferença estatística, em nível de 5\% de significância, entre ausência e presença de boro e letras maiúsculas entre diferentes níveis de cálcio.
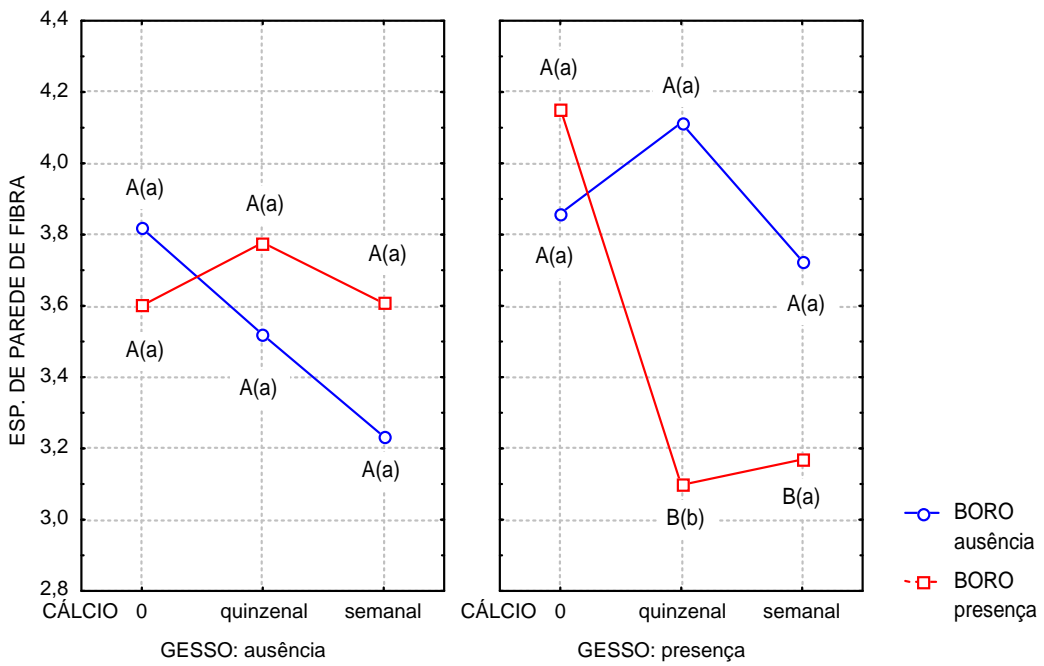

FIGURA 7 - Influência da interação tripla dos nutrientes sobre a espessura da parede de fibra em $(\mu \mathrm{m})$ do caule de Solanum gilo.

Letra minúscula distinta mostra diferença estatística, em nível de 5\% de significância, entre ausência e presença de boro e letras maiúsculas entre diferentes níveis de cálcio.

\section{Efeito dos tratamentos na composição da lignina}

A maioria das ligninas isoladas do caule de Solanum gilo Raddi submetidas aos tratamentos, apresentaram dominância de unidade guaiacila, entretanto as plantas que receberam $\mathrm{CaSO}_{4} / \mathrm{CaCl}_{2}$ (semanal e quinzenal) apresentaram altos teores de unidade siringila na proporção (G:S) de 1,2:1 e $08: 1$, respectivamente. O que sugere a participação do $\mathrm{Ca}^{++}$na formação dos precursores monolignóis dentro do citoplasma.

Ciênc. agrotec., Lavras, v. 30, n. 3, p. 394-401, maio/jun., 2006 


\section{CONCLUSÃO}

Os resultados mostraram que o íon $\mathrm{Ca}^{++}$interferiu significativamente na via dos fenilpropanoídes e na polimerização da lignina face às transformações observadas com relação à razão entre as unidades siríngilica e guaiacílica. O mecanismo de atuação do Boro e do cálcio são extremamente complexos, entretanto, de acordo com os resultados obtidos, pode-se sugerir que, estes elementos interagiram significativamente com as oxidases (peroxidases) na formação da lignina, o que de acordo com o nosso objetivo significa uma resposta satisfatória para fortalecer a autodefesa do jiloeiro. Os resultados também acenaram para novas perspectivas do ambiente natural, diminuindo os efeitos antrópicos dos agrotóxicos no ambiente e provavelmente economicamente viáveis. Acredita-se que flexibilidade anatômica do jiloeiro tem grande importância na adaptabilidade às novas condições. Neste sentido, os tratamentos com melhores resultados foram respectivamente: $\mathrm{CaSO}_{4} / \mathrm{CaCl}_{2}$ e $\mathrm{H}_{3} \mathrm{BO}_{3} / \mathrm{CaSO}_{4} / \mathrm{CaCl}_{2}$, aplicados semanal e quinzenalmente.

\section{REFERÊNCIAS BIBLIOGRÁFICAS}

BOSÍSIO, B. M. Avaliação de tendências evolutivas vegetais via quantificação lignoídica. 1996. $148 \mathrm{f}$. Dissertação (Mestrado) - Fundação Oswaldo Cruz, Rio de Janeiro, 1996.

BURGER, L. M.; RICHTER, H. G. Anatomia da madeira. São Paulo: Nobel, 1991. 154 p.

CAMPOS, H. Estatística experimental não paramétrica. 4. ed. [S.1.: s.n.], 1983. 349 p.

CAKMAK, I.; ROHMHELD, V. Boron deficiency-induced impairments of cellular functions in plants. Plant and Soil, The Hague, v. 193, n. 1/2, p. 71-83, 1997.

CARPIN, S.; CREVECOEUR, M.; GREPPIN, H.; PENEL, C. Molecular cloning and tissue-specific expression of an anionic peroxidase in zucchini. Plant Physiology, Washington, v. 120, n. 3, p. 799-810, 1999.

DAVIN, L. B.; LEWIS, N. G. Phenylpropanoid metabolism: biosynthesis of monolignols, lignans and neolignans, lignins and suberins. New York: Plenum, 1995.
EFFLAND, M. J. Modified procedure to determine acidinsoluble lignin in wood and pulp. Tappi, [S.1.], v. 60, n. 10, p. 143-144, 1977.

FAWZIA, S.; AL-YOUSIF, M. H.; AL-WHAIBI, S. O.; ELHIRWERIS. Influence of boron concentrations on some metabolites of date palm and sorghum seedlings. Journal of Plant Nutrition, Monticello, v. 17, n. 6, p. 1037-1052, 1994.

GOMES, F. P. Curso de estatística experimental. 11. ed. Piracicaba: USP, 1985. 466 p.

HUBER, D. M. The rules of nutrients and chemicals. New York: Academic, 1981.

LIN, S. Y.; DENCE, C. W. Methods in lignin chemistry. New York: Springer Verlag, 1992. 578 p. (Series in Wood Science).

MACLAUGHLIN, S. B.; WIMMER, R. Calcium physiology and its role in terrestrial ecosystem processes. New Phytologist, [S.1.], v. 142, p. 373-417, 1999.

MATOH, T.; KOBAYASHI, M. Boron and calcium, essential inorganic constituents of pectic polysaccharides in higher plant cell walls. Journal Plant Research, [S.1.], n. 111, p. 179-190, 1998.

PALAVAN-UNSAL, E.; AETIN, A.; KADIOGLU. Boron stress affects activity. Plant Peroxidase Newsletter, [S.1.], n. 15,p. 37, 1999. Disponível em: <http://Www.unige.chh LABPV/newsletters/news115/n15 157 html . Acesso em: 15 jan. 2006.

PENEL, C.; GREPPIN, H. S.; CARPIN, M.; CREVECOEUR. Binding of plant isoperoxidases to pectin in the presence of calcium. FEBS Letters, [S.1.], n. 343, p. 1-55, 1994. Disponível em: <http://Www.unige.ch/LABPV/newsletters/ 'newsl $14 / \mathrm{n} 14 \mathrm{p} 33 . \mathrm{htm}$ >. Acesso em: 26 jan. 2006 .

SANCHEZ, O. J.; PAN, A.; NICOLAS, G.; LABRADOR, E. Relation of cell wall peroxidase activity with growth in epicotyls of Cicer arietinum: effects of calmodulin inhibitors. Physiologia Plantarum, Copenhagen, v. 75, p. 275-279, 1989. 